\title{
Globalização e a Dinâmica Econômica: A Rede Empresarial Formada Pela Camnpal
}

\author{
Globalization and economic dynamics: business network formed by Camnpal
}

Vanessa Manfio*1

${ }^{1}$ Universidade Federal de Santa Maria, Santa Maria, Brasil.

\begin{abstract}
Resumo
No desenrolar dos acontecimentos que marcaram o mundo no cenário mundial, o capitalismo teve um papel importante na organização socioeconômica, cujo desenvolvimento deste sistema redesenhou novas configurações no espaço como: a formação de redes, revolução de tecnológica, empresas multinacionais, produção em massa, enfim são mudanças que provocam o entrelaçamento das relações em níveis globais, conectando vários lugares entorno da lógica de mercado. Assim, no mundo contemporâneo, muitas empresas procuram relacionar - se em redes permitindo sua competitividade e lucratibilidade no mercado comercial. Este é o caso da Cooperativa Agrícola Mista Nova Palma Ltda que através de sua dinâmica concentra vários serviços e empresas estabelecendo um complexo sistema de rede que, por sua vez, (re) estrutura o comércio e espaço regional da Quarta Colônia de Imigração Italiana/RS. Obviamente, esta interconexão regional - global somente é possível mediante a revolução das comunicações e tecnologia, proporcionando o a facilidade de fluxos e de controle das atividades. Neste sentido, o objetivo deste artigo é apresentar uma discussão teórica a cerca do capitalismo e da globalização, abordando especificamente o caso da CAMNPAL na formação de uma rede empresarial, dos quais exerce um incontestável papel na economia regional.
\end{abstract}

Palavras-chave: Globalização; rede; CAMNPAL.

\begin{abstract}
In the course of events that marked the world on the world stage, capitalism played an important role in the socio-economic organization, whose development of this system redesigned new configurations in space such as the formation of networks, technological revolution, multinational corporations, mass production, and so on. Nevertheless, these are changes that cause the intertwining of relationships in overall levels, connecting various places around the market logic. Thus, in today's worlds, many companies seek to relate through networks allowing its competitiveness and profitability in the commercial market. This is the case of the Mixed Agricultural Cooperative Nova Palma Ltd which concentrates its dynamics through various services and companies establishing a complex network system that, in its turn, restructures the trading and regional space of the Fourth Colony of Italian Immigration -RS. Obviously, this regional-global interconnection is only possible by the revolution in communications and technology, providing the ease of flow and activities control. In this sense, the objective of this paper is to present a theoretical discussion about capitalism and globalization, focusing specifically on the case of CAMNPAL in forming a business network, which plays an undeniable role I the regional economy.
\end{abstract}

Keywords: Globalization; network; CAMNPAL. 


\section{Introdução}

A discussão político-científica sobre as mudanças Ao longo dos tempos, o sistema capitalista estabeleceu novas relações, aperfeiçoando suas formas de obter lucro e comandar o mercado econômico. Tendo a revolução tecnológica como um importante papel nesta configuração de novas oportunidades de estruturas econômicas, desconsiderando as fronteiras físicas e as barreiras comerciais. Esta nova fase capitalista vivida pela sociedade, nos dias de hoje, é conhecida também como globalização mundial.

Dessa forma, com a globalização aparecem no cenário mundial novas articulações como as redes, os blocos econômicos, os territórios globais, entre outros, cujas proximidades geográficas não representam mais o cerne das negociações econômicas, mas sim os interesses de diversos grupos empresariais.

Obviamente que estas mudanças vividas pelo mundo na contemporaneidade representam muitas dificuldades e exclusões, seja pelo avanço dos conflitos mundiais, ambientais ou mesmo pela pobreza e dependência econômica de mercados sob os grupos hegemônicos do poder.

Neste sentido, este artigo visa discutir sobre os aspectos relevantes da conjuntura mundial da globalização abordando, especificamente o desencadeamento de redes empresariais, tendo como exemplo a formação de uma rede a partir das negociações da Cooperativa Agrícola Mista Nova Palma Ltda (CAMNPAL). Sendo estas redes importantes para manutenção da competitividade e desenvolvimento econômico e regional.

\section{Métodos e Metodologia}

Neste artigo, obedecendo aos objetivos da pesquisa, foi utilizado como referências teóricas os seguintes autores: Barquero (2001), Font; Rufí (2006), Santos (2006 e 2008), Porto-Gonçalves (2006), Lencione (2006), Lipnack; Stamps (1994), Castells (1999), Manfio (2011) entre outros, afim de desenvolver um embasamento teórico que dê conta das colocações dos dois pontos-chaves do artigo: rede e globalização.

Na questão método científico, utilizou-se a abordagem dialética para conduzir os caminhos da pesquisa, pois o mesmo permite a compreensão e a interação entre as diversas variáveis que influenciam o objeto de estudo.

É neste entendimento que Milton Santos (1985) coloca que ao analisar o espaço dialeticamente é possível compreender a evolução da organização do espaço, estabelecendo relação entre forma e a função no desenrolar do tempo e ainda estudando a realidade (concreto) e o movimento.

Podemos ainda dizer que a pesquisa pode ser classificada como bibliográfica, já que o desenvolvimento nas discussões tem fundamento em material publicado em livros, dissertações, artigos e redes eletrônicas (Ver- gara, 2007).

Neste sentido, as atividades metodológicas de pesquisa desenvolvem-se em várias etapas, iniciando pelo levanta $\neg$ mento de dados, que compreende o levantamento bibliográfico sobre a globalização, a rede empresarial e a CAMNPAL. Posteriormente uma entrevista com membros da cooperativa e pessoas antigas da cidade de Nova Palma- RS, além de dados técnicos adquiridos junto à própria instituição pesquisada. Numa última etapa, será realizada a análise e a discussão sobre os dados obtidos.

Contudo, ao utilizar esta abordagem metodológica buscamos discutir e contribuir para as análises a cerca da globalização e da temática das redes, cada vez mais frequentes no mundo pós-moderno.

\section{Globalização: Alguns Apontamentos Teóricos}

No contexto contemporâneo, a globalização tem sido alvo de muitas discussões entre as diversas linhas do pensamento geográfico e social, devido há uma série de transformações mundiais.

Para Massey (2008) a globalização é atualmente, um dos termos mais frequentemente usados e mais poderosos em nossas imaginações geográficas e sociais.

Assim, na tentativa de definir a globalização pode-se dizer que esta trata-se de um conjunto de mudanças nas esferas: econômica, financeira, comercial, social, cultural e nos sistemas produtivos, intensificando a inter-relação dos diversos países.

Segundo Font; Rufí (2006) a globalização não engloba apenas questões econômicas, mas as questões políticas, culturais que abraça um leque de aspectos da vida cotidiana.

Pode-se dizer que a globalização em termos gerais seja um processo relacionado à estruturação da produção capitalista, associado às transformações das técnicas, formas de produção, localização, circulação e acumulação dentro do capitalismo, podendo ser então considerada como uma nova fase do capitalismo.

Na visão de Santos (2008, p. 23) “a globalização é de certa forma, o ápice do processo de internacionalização do mundo capitalista."

Reforça Gonçalves (1998) que a Globalização pode ser definida como a inter-relação entre três diferentes processos ao longo das três últimas décadas e, afetam as esferas produtiva, comercial, financeira e tecnológica das relações econômicas mundiais. Estes processos são: a maior integração econômica dos sistemas nacionais a nível mundial, acirramento da concorrência dos mercados internacionais e a incrível expansão dos fluxos internacionais de bens, serviços e, principalmente, de capitais - no seu sentido financeiro.

Nota-se que no final do século XX, graças aos avanços da ciência produziu-se um sistema de técnicas precedido 
pela informação que passaram a exercer um papel de elo com as demais unindo-as e assegurando ao novo sistema técnico uma presença planetária. (SANTOS, 2008). Este sistema planetário de união entre ciência e informação passou a ser considerada globalização.

Ainda para Santos (2006, p. 159) “Essa união entre técnica e ciência vai dar -se sob a égide do mercado. E o mercado, graças exatamente à ciência e a técnica, torna -se um mercado global.

Sob este ângulo, Font; Rufí (2006) discutem sobre a internacionalização, transnacionalização e globalização, dos quais o enfoque popular aborda em muitos casos, estas palavras como sinônimos. Entretanto, estes autores conceituam a primeira como uma inter-relação econômica e política, entanto a segunda refere-se a organização da produção transfonteiriça em âmbito supranacional. Já a globalização engloba ambas, sendo a capacidade com que os sistemas de comunicação e transportes tornam os mercados uma totalidade.

Além disso, este período através de vários recursos tecnológicos, permite também a conexão entre o espaço local e o regional, conforme PORTO-GONÇALVES (2006, p. 12) "Globalização, mundialização e planetarização são palavras que, cada vez mais, começam a construir uma nova comunidade de destino, em que a vida de cada um já não se acharia mais ligada ao lugar ou ao país que nasceu ou, pelo menos, não se acharia mais do mesmo modo como se achava antes."

Nesse sentido, Santos (2006) afirma que graças aos progressos conjuntos da ciência, da técnica e da informação, a noção de totalidade ganha ênfase, sendo entendida como o conjunto de todas as coisas e de todos os homens, em sua realidade, isto é, em suas relações, e em seu movimento.

E quando se aborda a noção de movimento nos reportamos ao desenvolvimento das redes e territórios flexíveis, característica desta nova era da globalização.

Diante disso, a informação, dissipada pelo território por meio de redes técnicas, passa a ser chave para a produção e para a extração da mais-valia cada vez mais global. Ainda, o arranjo de tais redes reestrutura o conteúdo dos lugares, as distâncias, as velocidades, as escalas, os fluxos e as relações estabelecidas entre os agentes, envolvidos tanto na produção da riqueza, como na organização espacial. (BOMTEMPO, 2012).

Ressalta Rattner (1995), a globalização tem início no pós-guerra, cujo período era caracterizado pela rápida expansão e integração da economia mundial, baseado no aumento das relações comerciais e do crescimento dos investimentos externos.

Neste contexto, a globalização tem sua ascensão, aproximadamente por volta de 1970, apresentando como características: a homogeneização cultura e econômica, a expansão das corporações para regiões fora de seus contornos geopolíticos, a revolução tecnológica nas comunicações e na eletrônica e a presença de blocos comerciais.
Entretanto, esta homogeneização profanada pela globalização, não se torna real, pois nem todos os lugares apresentam hoje, os mesmos aspectos, cuja heterogeneidade é destaque dos espaços e sociedades do novo milênio.

Conforme, Santos (2008) neste mundo globalizado erige certo número de fábulas como: a homogeneização do mundo, onde pelo contrário vê-se as diferenças locais mais aprofundadas e a noção de tempo e espaço numa totalidade não atingem a todos, já que os pobres não tem acesso ao mundo em suas mãos.

Ainda Santos (2008) argumenta que o mundo globalizado está impondo-se como uma fábrica de perversidades como: desemprego, pobreza, conflitos entre outros.

Numa outra perspectiva, o espaço mundial vem sendo marcado pela noção de rede, cuja configuração ultrapassa as fronteiras nacionais. As redes são características do processo de globalização, onde tudo se encontra interligado pelos sistemas de comunicação e informação.

Dentro deste enfoque, Santos (2006) coloca que graças aos progressos técnicos e às formas atuais de realização da vida econômica, cada vez mais as redes são globais: redes produtivas, de comércio, de transporte, de informação. Estas redes tornam-se incompreensíveis nas manifestações locais, regionais e globais.

Argumenta ainda Santos (2006) que os avanços técnicos e o processo de globalização têm estruturado o mundo em redes, dos quais todos os espaços podem estar interligados, dessa maneira local e global se encontram, estando o local dentro da lógica de mundo e visto pelo mundo, assim como o global passa a ser introduzido ao local e regional.

Diante disso, observa-se que nas últimas décadas presenciamos a incorporação de áreas até então restritas às atividades de cunho local e regional à produção globalizada, contribuindo para que as diversas fases do processo de produção pudessem ser fragmentadas e ao mesmo tempo articuladas por meio das redes. (BOMTEMPO, 2012).

Em suma, as mudanças mundiais, reflexos da globalização tem alterado a forma de organização espacial e as relações socioeconômicas. Assim, como tem contribuído para a proliferação de problemas mundiais de diversas ordens, e afunilado a noção de tempo e espaço, com a presença da revolução tecnológica, impondo ao mundo transformações, jamais vistas anteriormente.

\section{A Formação de Redes no Espaço Con- temporâneo: O Caso da Rede Empresarial da Camnpal}

O processo de globalização marcado pela internacionalização do capital e a revolução tecnológica permite a aproximação de lugares e a expansão produtiva. Obviamente, os efeitos da globalização no cenário produtivo tem resultado na formação de redes, facilitando a 
comercialização.

Conforme Barquero (2001): A globalização gerou novos processos de desenvolvimento, organização espacial e produtiva, a formação de redes urbanas e econômicas e as novas relações entre lugares diferentes que são superadas pelos sistemas de informação e infraestrutura.

Destaca Benaduce (1999) que:

“A complexidade das mudanças tecnológicas e a extensão delas mostram novas formas de produzir e circular. Essa mudança substancial do modelo capitalista foi marcada por características organizacionais como a concentração, flexibilidade, a descentralização e o acontecer em redes." (BENADUCE, 1999, p.15).

Diante desta "era global" a formação de redes é essencial para o desenvolvimento econômico, especialmente de empresas. Para isto, Barquero (2001, p. 101) afirma: "A formação e expansão de redes de empresas ocupa uma posição central nos processos de desenvolvimento endógeno."

Com a globalização observa-se a presença de novos arranjos espaciais e ainda a dinâmica em rede proporciona a reorganização do espaço e a redefinição da circulação de pessoas, mercadorias e informações.

Salienta Lencione (2006, p. 66): “Por meio de redes são tecidos múltiplos e complexos liames entre empresas, concorrendo para a tecedura de uma trama por onde transitam fluxos."

Neste sentido, a multiplicidade e diversidade das redes atuais, principalmente as ligadas à produção, constituem-se forças fundamentais para economia globalizada. Essas redes expressam as relações de circulação de capitais, sendo o espaço mediador necessário a reprodução do capital em escala globalizada. (LENCIONE, 2006).

Com isso, na atualidade, muitas organizações empresariais têm se organizado em rede, a fim de adquirirem vantagens econômicas e desenvolvimento. Entretanto, a rede empresarial não diz respeito apenas na empresa global, mas sim de um sistema produtivo dependente da combinação de alianças estratégicas e projetos de cooperação entre empresas, unidades descentralizadas de cada empresa de grande porte e rede de pequenas e médias empresas que se conectam entre si/ou com grandes empresas ou redes empresariais. (CASTELLS, 1999).

Nesta lógica, a rede empresarial é definida como sendo um conjunto ou grupo de participantes, unidos com um propósito comum e dotados de múltiplas conexões, estas de diferentes níveis organizacionais. (LIPNACK; STAMPS, 1994).

Ressalta LEON (1998), as redes de empresas são formadas inicialmente com o objetivo de reduzir incertezas e riscos, organizando atividades econômicas a partir da coordenação e cooperação entre empresas, existindo a possibilidade destas configurarem-se como redes flexíveis de pequenas e médias empresas, como clusters de empresas (agrupamentos), ou como redes de cooperação.

Assim como, a rede pode promover o desenvolvimento através das articulações e estratégicas que estão envolvidas na estrutura em rede, a mesma pode provocar o enfraquecimento ou dependência, principalmente dos menores centro ou empresas aos maiores, resultando numa fragilidade do território.

Dessa forma, a organização em rede produz transformações territoriais e des/construção e reconstrução implicando em novas espacialidades e relações que são produtivas ao desenvolvimento.

Pode-se dizer que no espaço contemporâneo a noção de rede também se aplica à economia mundial, cuja configuração ultrapassa as fronteiras nacionais, as redes são características do processo de globalização, onde tudo se encontra interligado pelos sistemas de comunicação e informação.

Todavia, o termo rede não é recente, tampouco a preocupação em entendê-lo, porém hoje, cada vez mais, ela se tornou instrumento e forma de organização do espaço. (DIAS, 1995). Dessa forma todos os espaços são marcados por dinâmicas em rede e é inevitável deixar de entender-las a fim de abordar o desenvolvimento territorial ou simplesmente espacial.

Sabe-se que os avanços técnicos e o processo de globalização vêm estruturando o mundo em redes, dos quais necessita-se em vias de regras do mercado entender as conexões em redes produtivas e comerciais, cuja integração é o viés de conduta do sistema e lógica da globalização. Com isso, na atualidade, muitas organizações empresariais ou mesmo cidades se organizam em rede, a fim de adquirirem vantagens econômicas e desenvolvimento.

As redes de empresas contribuem com informações sobre negócios, assessoramento técnico, recursos financeiros e matérias e firmam alianças estratégicas. Assim como, a formação e a expansão de redes de empresas ocupam uma posição central nos processos de desenvolvimento endógeno, uma vez que através destas ocorrem o surgimento e o crescimento das empresas, difusão das inovações e processo de mudança estrutural. (BARQUERO, 2001).

Pensando nisso, Thesing (2005, p. 6) defende que:

(...) formação de redes é uma forma de as empresas se organizarem para competirem em escala local, regional e global, sem terem que arcar sozinhas com os custos e investimentos, as incertezas e riscos, presentes no movimento de globalização da economia (...).

Neste contexto, as atividades da Cooperativa Agrícola Mista Nova Palma Ltda, localizada na região da Quarta Colônia de Imigração Italiana - centro do Rio Grande do Sul- têm articulado um conjunto de empresas que passam a desempenhar prestação de serviços e comércio para a CAMNPAL, formando uma rede empresarial, lócus da dinâmica do capitalismo atual. 
Partindo destas colocações, a Cooperativa Agrícola Mista Nova Palma Ltda, surge mediante a uma necessidade de comercialização agrícola, já que a falta de infraestrutura dificultava a comercialização na região, e apoiado pela congregação religiosa, (cuja presença do sacerdote era vista pela cultura italiana como liderança religiosa, e muitas vezes, como líderes políticos e econômicos).

Com isto, na região da Quarta Colônia de Imigração Italiana o Padre Luiz Sponchiado foi um importante representante da comunidade, estruturando a vida dos seus fiéis, e interferindo no desenvolvimento econômico regional, sendo a criação da CAMNPAL um exemplo do seu papel na estruturação da região.

Destaca-se que um aspecto importante na cultura italiana é a religiosidade, sendo o descendente italiano é considerado um povo muito religioso, e tal afirmação pode ser vista pela organização do espaço desta etnia, com a presença de inúmeras capelas, grutas entre outros símbolos. (BRUM NETO, 2007).

Nesta abordagem, entre os descendentes italianos, o padre exercia forte influência sobre a comunidade local, sabe-se que os italianos eram muito religiosos e seguiam fielmente a liderança do padre e seus ensinamentos. (MANFIO, 2011).

Deste modo, na década de 1960 surge a CAMNPAL no município de Nova Palma- RS, e nos anos posteriores, começou a delinear novas unidades expandindo seus negócios criando filiais e associando-se a outras empresas da Região da Quarta Colônia/RS. Coloca (MANFIO, 2011, p. 74): “A cooperativa mostrou significativo crescimento econômico, reforçando as perspectivas de desenvolvimento dos colonos rurais."

Nesta lógica, a cooperativa vai espraiando suas unidades pela região e mantendo relações com outras empresas e cidades gaúchas, denotando desenvolvimento em suas atividades, além de estabelecer um comércio significativo, envolvendo o regional/global, especialmente na importação de produtos de fora do país, como por exemplo: o sêmen bovino importada da França e a lentilha e o feijão, principalmente da Argentina (já que a produção desse grão tem sido insuficiente para atender a demanda de consumidores das marcas Bella Dica e Caldo de Ouro, próprias da CAMNPAL). (Ilustração 1).

Deste modo, o beneficiamento de feijão na década de 1980 foi um marco no início das atividades da agroindústria que vem crescendo e ampliando o mix de produtos, já comercializados no Brasil inteiro, através das marcas Bella Dica e Caldo de Ouro. (CAMNPAL, 2012).

Assim, como a CAMNPAL também fornece seus produtos as empresas localizadas no Porto de Rio Grande, este é o caso da soja in natura é levada da Região da Quarta Colônia de Imigração Italiana para o Porto de Rio Grande, cujo produto é fornecido para as indústrias, tais como: Bianchini S.A., Cargil S. A., ADM, das quais serão exportadas para demais países, especialmente China e Argentina.
Neste sentido, Hoff, et.al. (2009, p.155-156) discute sobre este aspecto "a maior parte da soja acaba sendo comercializada com as trades, como Bunge, Cargill e ADM, e uma pequena parte utiliza-se de contratos diretos com indústrias importadoras."

A CAMNPAL também comercializa soja in natura para a indústria GRANOL de Cachoeira do Sul, dos quais traz de Caçapava do Sul, fertilizantes e calcários. (Ilustração 1).

Convém destacar que atualmente, a CAMNPAL apresenta filiais em vários municípios da Quarta Colônia de Imigração Italiana- RS (região formada a partir do quarto núcleo de colonização italiana no RS, dos quais fazem parte os municípios de: Nova Palma, Faxinal do Soturno, Pinhal Grande, Ivorá, Silveira Martins, Dona Francisca e São João do Polêsine).

A primeira filial na Quarta Colônia foi em Dona Francisca, posteriormente em São João do Polêsine, este último que conta com moinho de trigo, onde hoje é produzida a Farinha Bella Dica. Em 2012, foi à vez da criação de uma unidade em Faxinal do Soturno com supermercado.

Além disso, a CAMNPAL possui uma unidade e parcerias com a cooperativa de Júlio de Castilhos. Acompanhando o processo de expansão de fronteiras agrícolas, a instalação da unidade da CAMNPAL em Val de Serra- Júlio de Castilhos- representou uma estratégia para o desenvolvimento da produção e logística. (CAMNPAL, 2012).

Nesta perspectiva, muitos serviços de industrialização das marcas: Bella Dica e Caldo de Ouro são processados em outros municípios por empresas terceirizadas. Por exemplo, a industrialização do leite UHT que é realizada pela empresa Santa Rita Comércio, Indústria e representações Ltda, localizada no município de Fazenda Vila Nova- RS.

É relevante o papel exercido pela Cooperativa Agrícola Mista Nova Palma Ltda na atração de outras empresas e agências bancárias à região, exemplo do Banco Sistema de Crédito Cooperativado (SICREDI) e da Cooperativa de Crédito Rural com Interação Solidária (CRESOL), e no dinamismo econômico junto aos órgãos públicos para melhorias de infraestrutura e serviços. (MANFIO, 2011).

A Cooperativa Agrícola Mista Nova Palma Ltda mostrou incontestável crescimento econômico e espacial. Este desenvolvimento significativo produziu sobre o espaço novas espacialidades e estruturas, assim como a formação de uma rede empresarial.

Esta dinâmica da CAMNPAL em rede permite a expansão das negociações desta cooperativa com as demais empresas, mantendo a competição e desenvolvimento frente ao avanço do capitalismo.

Assim evidencia-se que neste novo período em que vive a humanidade, a globalização, torna-se necessário novas formas de atuação de empresas e cooperativas para proporcionar sua manutenção no mercado e expansão comercial, assim como fez a Cooperativa Agrícola 


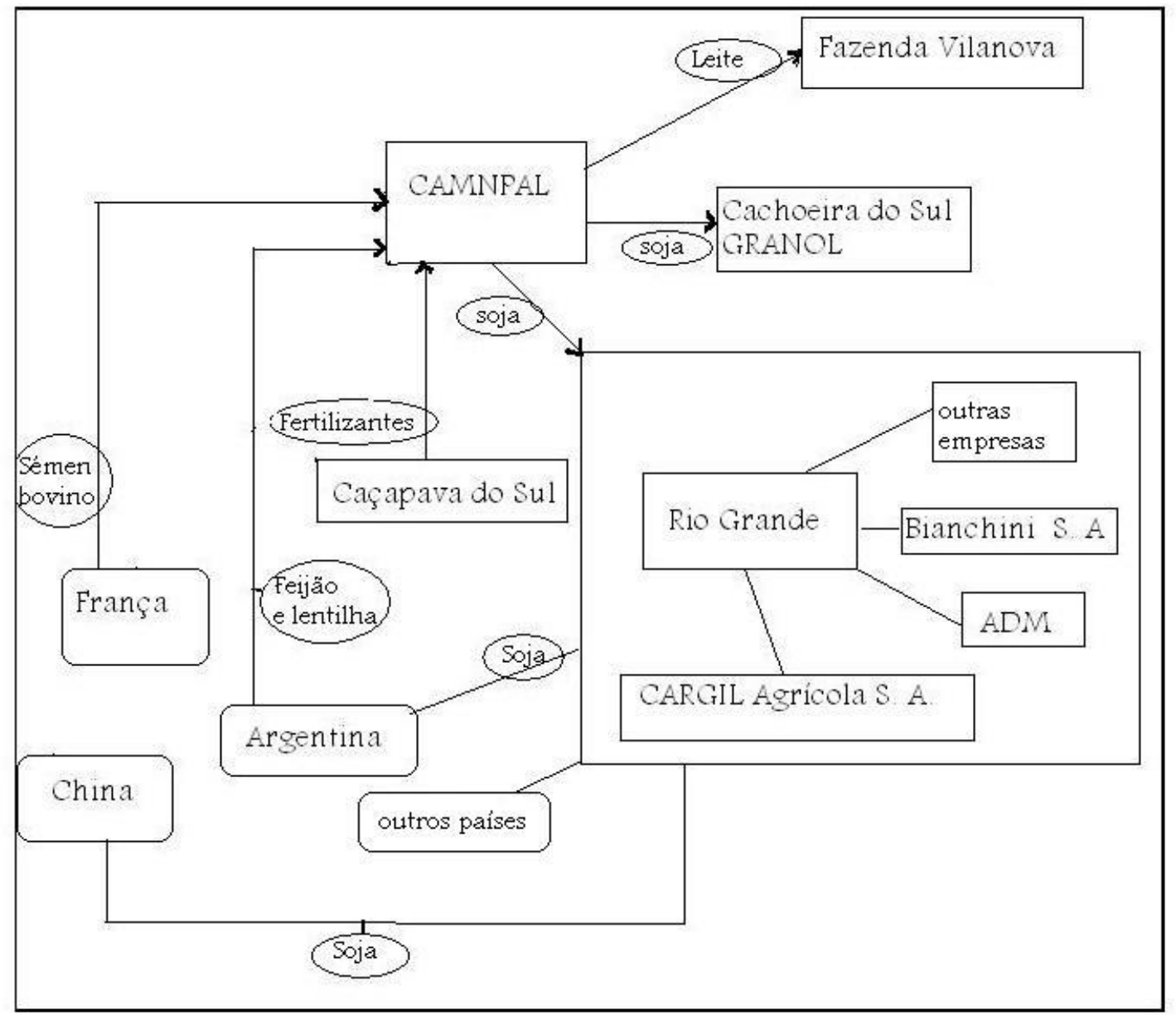

Ilustração 1: Esquema da Comercialização da CAMNPAL - 2010

Fonte: MANFIO (2011, p. 94).

Mista Nova Palma Ltda no desenvolvimento de uma rede empresarial.

Neste âmbito, a produção e circulação de mercadorias no processo de globalização faz emergir novas organizações econômicas, ligadas a criação de sistemas espaciais com a concentração das empresas em rede que modificam o conteúdo e a funcionalidade de cidades e regiões, gerando espaços de competitividade. (BOMTEMPO; SAVÉRIO, 2012).

Porém, é significativo afirmar que a revolução tecnológica tem permitido este entrelaçamento de serviços entre as diversas empresas da rede, assim como a administração do circuito reticular.

Entretanto, a expansão do poder da CAMNPAL no âmbito regional têm gerado fragilidades e implicações socioeconômicas, à medida que as propriedades rurais e economias regionais, ficam dependentes da cooperativa e ainda os pequenos estabelecimentos comerciais locais enfrentam dificuldades em competir com os produtos oferecidos pela cooperativa.

Pensando nisso, as perspectivas de desenvolvimento e trajetórias que a Região da Quarta Colônia de Imigração Italiana tomará, dependerão dos atores locais, dos estu- dos, pesquisas e das políticas públicas, aproveitando os potenciais locais e respeitando as fragilidades imposta pelo meio ambiente. Sobretudo, a expansão e inter-relação da CAMNPAL na rede empresarial abordada anteriormente permitirão o constante desenvolvimento regional e a (re) estruturação do espaço urbano da região.

\section{Considerações}

Na atualidade, a globalização, apresenta como características: a internacionalização do capital, a revolução tecnológica, a formação de alianças econômicas, a formação de redes empresariais e territoriais que buscam se manter diante da forte competitividade atual, enfim a globalização provoca inúmeras mudanças mundiais.

Sobretudo, estas mudanças atingem a todos os lugares, até mesmo as pequenas cidades brasileiras, como é o caso da Região da Quarta Colônia de Imigração Italiana/RS que através da dinâmica da Cooperativa Agrícola Mista Nova Palma Ltda proporciona a conexão da região com a economia global e promove o desenvolvimento e modernização regional. 
É importante ressaltar que a CAMNPAL surgiu mediante a uma cooperação entre pequenos agricultores locais que apresentavam dificuldades de comércio. Entretanto, ao longo dos tempos, esta cooperativa amplia seus negócios e empresas, estabelecendo relações comerciais e empresariais com outras empresas e cidades gaúchas, formando uma rede empresarial.

No entanto, a estruturação reticular das atividades da CAMNPAL somente foi possível, devido aos avanços tecnológicos da atual fase vivida pelo mundo, a globalização. Assim, novas estruturas e formas de competitividade surgem no contexto da globalização, sendo as redes uma delas. Sabe-se que as redes, no contexto atual são essenciais para promover o desenvolvimento e comércio global, pois ultrapassam limites e integram economias.

Neste mesmo raciocínio, as redes empresariais não referem-se apenas a uma empresa que manter relações globais, mas um conjunto de empresas, associados a infraestruturas capazes de assegurar a conexão de espaços e empresas.

Diante disso, no século XXI observou-se a intensificação do sistema em rede, proporcionando mudanças significativas em diferentes setores da economia e sociedade, juntamente com a expansão do capitalismo em nível mundial e articulada a diferentes estratégias e segmentos.

Em síntese, ao retornar a questão da formação da rede empresarial da CAMNPAL envolvendo a Quarta Colônia de Imigração Italiana, pode-se destacar que a expansão da atuação desta no espaço regional têm sido expressivo para economia das pequenas cidades e reestruturação urbana, entretanto, o desenvolvimento desta região dependerá também das políticas públicas e dos agentes econômicos, a fim de minimizar as fragilidades e implicações econômicas que a CAMNPAL venha a desempenhar com a pequena propriedade privada.

\section{Agradecimentos}

A professora Drª . Gilda Maria Cabral Benaduce, do curso de geografia da Universidade Federal de Santa Maria, pelo apoio. Além disso, agradecimentos a Cooperativa Agrícola Mista Nova Palma Ltda, pela colaboração e disponibilidade de material para o desenvolvimento deste trabalho, especialmente a funcionária Silmara Fagan.

\section{Referências}

BARÉA, N. M. M. S. Redes de Produção e Dinâmica na Organização das Espacialidades. 2008.

135f. Dissertação (Mestrado em Geografia) Universidade Federal de Santa Maria, Santa Maria, 2008.
BARQUERO, A. V. Desenvolvimento endógeno em tempos de globalização. Tradução: Ricardo Brinco. Porto Alegre: Fundação de Economia e Estatística, 2001.

BENADUCE, G. M. C. Intensificação das Redes de Informações e Novas Espacialidades no Paraná. 1999. 212f. Tese (Doutorado em Geografia) Universidade Estadual Paulista, Presidente Prudente, 1999.

BENKO, G. Economia, espaço e globalização: na aurora do século XXI. $3^{a}$ ed. São Paulo: HUCITEC, 2002.

BOLAÑO, C. R. S. (Org.). Globalização e Regionalização das Comunicações. São Paulo: Editora EDUC, 1999.

BOMTEMPO, D. C. Dinâmicas Territoriais e Interações Espaciais: A Configuração do Circuito Espacial da Produção da Nestlé S/A. Caderno Prudentino de Geografia, Presidente Prudente, n.34, v.1, p.72-96, jan./jul.2012.

BOMTEMPO, D. C.; SAVÉRIO S. E. Circuitos Espaciais da Produção e Novas Dinâmicas do Território. Mercator - Revista de Geografia da UFC, vol. 11, núm. 26, set./dez, 2012, pp. 27-46.

BRUM NETO, H. Regiões Culturais: A construção de identidades culturais no Rio Grande do Sul e sua manifestação na paisagem gaúcha. 2007. 328f. Dissertação (Mestrado em Geografia) Universidade Federal de Santa Maria, Santa Maria, 2007.

CAMNPAL. Dados da CAMNPAL. Nova Palma. Disponível em: <http:// www.camnpal.com.br>. Acesso em: 16 de out. 2012.

CASTELLS M. A sociedade em rede. A era da informação: economia, sociedade e cultura. São Paulo: Editora Paz e Terra, v.1, 1999.

CASTRO, A. M. G. Análise da competitividade de cadeias produtivas. Manaus: EMBRAPA, Ago., 2000. Disponível em: <http://www.temasemdebate. cnpm.embrapa.br/textos>. Acesso em: 29 jan. 2008.

DIAS, L. C. Redes: emergência e organização. In: Geografia: Conceitos e Temas. Org.: Castro, I. E. de; Gomes, P. C. de C.; Corrêa, R. L. Rio de Janeiro: Bertrand Brasil, 1995. p. 141-162.

FONT, J.N., RUFÍ, J.V. Geopolítica, identidade e globalização. São Paulo: Annablume, 2006. 
GONÇALVES, R. Globalização econômica e vulnerabilidade externa. In: Seminário Economia Global, Integração Regional e Desenvolvimento Sustentável. Universidade Federal Fluminense, Rio de Janeiro, 1998.

Hoff, D. N. et.al. Efeitos Sistêmicos em Relações Contratuais Ocasionados pelo Oportunismo: Um Estudo do Comércio da Soja entre China e Brasil em 2004. Revista de Administração da UNIMEP, v. 7, n.1, p. 138-162, Janeiro / Abril - 2009.

LENCIONE S. Da cidade e sua região à cidade-região. In: SILVA, J.B. da; LIMA, L. C.; ELIAS, D. (Org.). Panorama da Geografia Brasileira I. 1ed. São Paulo: Annablume, 2006.

LEON, M. E. Uma Análise de Redes de Cooperação das Pequenas e Médias Empresas do Setor das Telecomunicações. 1998. Dissertação (Mestrado em Engenharia de Produção) - Universidade de São Paulo, São Paulo, 1998.

LOPES, A. P. Análise de indicadores econômicofinanceiros e sociais na gestão de cooperativas agropecuárias na região central do estado do Rio Grande do Sul. 2009. 138f. Dissertação (Mestrado em Extensão Rural) - Universidade Federal de Santa Maria, Santa Maria, 2009.

MANFIO, V. O papel da CAMNPAL na (Re) estruturação do espaço urbano de Nova Palma- RS. 2011. 128f. Dissertação (Mestrado em Geografia) Universidade Federal de Santa Maria, Santa Maria, 2011.

MASSEY, D. Pelo espaço: uma nova política da espacialidade. Rio de Janeiro: Bertrand Brasil, 2008.

MAZZALI, L. O processo recente de reorganização agroindustrial: do complexo à organização "em rede". São Paulo: Editora UNESP, 2000.

PORTO- GONÇALVES, C. W. A globalização da natureza e a natureza da globalização. Rio de Janeiro: Civilização Brasileira, 2006.

RATTNER, H. Globalização: Em direção a um mundo só? Estudos Avançados. v. 9, n. 25, São Paulo, Set./ Dez. 1995.

SANTOS, M. Espaço e Método. São Paulo: Nobel, 1985.

. Circuitos espaciais da Produção: um comentário. In: SOUZA, Maria Adélia A. de (Org.). A construção do Espaço. São Paulo: Nobel, 1986.
A natureza do espaço. Técnica e tempo. Razão e emoção. São Paulo: EDUSP, 2006.

Por uma outra globalização: do pensamento único à consciência universal. Rio de Janeiro: Record, 2008.

SAQUET, M. A. A construção do espaço em Nova Palma/RS. Francisco Beltrão/PR: Grafit, 1996.

THESING, N. J. Redes de Cooperação: novas formas de pensar e agir. 2005.

VERGARA, S. C. Projetos e relatórios de pesquisa em administração. São Paulo: Atlas, 2007. 